Commentary on: Potter, N. 2003. Commodity/body/sign: Borderline personality disorder and the signification of selfinjurious behavior. Philosophy, Psychiatry, \& Psychology 10:1-16.

\title{
Self-Injury: Symbolic Sacrifice/Self-Assertion Renders Clinicians Helpless
}

\section{Christa Krüger}

Keywords: feminism, iconic communication, moral conflict, oppression, psychiatrist/psychologist roles, social norms

Potter's paper considers self-injury in women diagnosed with borderline personality disorder (BPD) to be a form of body modification where the body is used to communicate meaning. She touches on symbolism as a possible explanatory theory for this sort of self-injury. She also refers to the culture of body commodification as underlying self-injury. She then argues that clinicians have a duty to give uptake to the patient's own interpretations about the meaning of the self-injury. Giving uptake is a virtuous approach for ethical interactions with people diagnosed with BPD who self-injure, and it aims to preserve the communicator's integrity, along with other benefits. Potter offers five maxims for giving uptake properly. However, I shall argue that giving uptake can be very difficult for clinicians, and that an appreciation of this difficulty depends on an expansion and linkage of some of the theories that she touched on. Self-injury is revisited experimentally as a double-edged sword of symbolic sacrifice and iconic-symbolic self-assertion. This revisiting aims to illustrate how clinicians might be caught in a double bind, where giving uptake properly might be very difficult if not more or less doomed to fail.

Potter's paper starts by situating self-injury in a broader discourse of body modifications. In this discourse the body is being used as a text, a tool to communicate meaning. The meaning that is communicated might be difficult or impossible to articulate otherwise (by using words, for example). The meaning of the communication is embedded in a context of social, cultural, religious, political, and other norms. Potter explores possible interpretations of the meaning of self-injury in women with BPD, including an interpretation of self-injury as symbolic sacrifice. She suggests that a cultural understanding/nonunderstanding of the meaning of a particular instance of self-injury is an important determinant of whether such self-injury is considered pathological/nonpathological. She then shifts the focus to the present-day culture in which women's bodies are commodified and objectified, and 
where women become alienated from their bodies. Self-injury might then be interpreted as an attempt to re-own one's body as a part of oneself. This re-owning is a socially transgressive act that violates repressive norms for the bodies of women.

Notwithstanding these possible significations of self-injury, Potter then argues that clinicians have a duty to give uptake to the patient's own interpretations, instead of jumping to conclusions (my oversimplification) about the meaning of the self-injury. Giving uptake, then, constitutes a framework for ethical interactions with people diagnosed with BPD who self-injure, and it aims to preserve the communicator's integrity. Potter offers five maxims for giving uptake properly.

At the risk of losing their essence, I translate the five maxims for practising psychiatrists as involving the following: critical self-reflection about one's own conceptual framework and cultural context: being receptive to the patient's conceptual framework and cultural context; giving the patient the benefit of the doubt; being open to the emergence of new meanings of self-injury; and keeping a range of possible interpretative options open, rather than insisting on having the final word. We should try to understand what the world looks like from the patient's position. All of this requires some moral effort.

Potter describes a number of benefits that result from giving uptake. Giving uptake is a crucial corrective to the human tendencies of becoming overly committed to prevailing societal norms and conceptual schemes (stuck in our ways), of imposing our views on others, and of silencing or distorting the communications of our patients. Giving uptake allows clinicians to be dialogically responsive and to treat patients with respect and dignity. Giving uptake fosters trust in a therapeutic relationship where clinicians do not exploit their patients' vulnerabilities. Giving uptake also allows for new knowledge, potentially more accurate knowledge, to emerge, and lessens the risk of ending up with mistaken belief.

I agree that this framework of five maxims constitutes a virtuous approach to people who self-injure. Indeed, it constitutes a virtuous approach to any patient, or for that matter, to any fellow human being. The five maxims are reminiscent of the stance of curiosity and neutrality (i.e., as neutral as our own values and beliefs allow) that is basic to therapeutic approaches based on systems theory (Cecchin, 1987; Selvini et al. 1980). This stance has been put to good use in various brands of family therapy (Barker, 1992; Boscolo et al. 1987; Campbell and Draper, 1985).

Whereas clinicians might subscribe to the ideal of giving uptake, I argue that we often fail at giving uptake to patients diagnosed with BPD who self-injure. We fail for good reasons - reasons beyond ourselves as individuals and as members of a profession. These good reasons are not immediately obvious, though. Furthermore, these reasons are unlikely to emerge during patient- 
clinician interaction, as I shall explain. We need to return first to explanatory theories, despite Potter's view that explanatory theories should not "stand in for the hard work of interactive patientclinician communication.”

I suggest that an expansion and linkage of some of the reviewed possible meanings of selfinjury (notably the meanings of sacrifice and of body commodification) might elucidate possible obstacles to giving uptake properly. Such an expansion might demonstrate how clinicians’ prior intentions to give uptake within the traditional context of patient-clinician communication, can be frustrated, and how their attempts at helping can be misguided. The following experimental interpretation of self-injury as symbolic sacrifice and iconic-symbolic self-assertion aims to illustrate how clinicians might find themselves in a double bind, where giving uptake properly might be very difficult, if not doomed to fail.

I draw on three contributions by Szasz to explore further possible meanings of self-injury that might interfere with giving uptake. The first is his analysis of hysteria as a paradigm of mental illness (Szasz, 1961). He considers hysteria as "protolanguage”, made up of iconic symbols that convey the message "I am sick, therefore...take care of me.” This indirect, metaphorical, nondiscursive language relies on the rule in this medical era that helpless or disabled people should be helped. Furthermore, the iconic body signs have object-seeking value; they exert a response from the object (e.g., spouse or therapist) that is difficult to prevent and that is more powerful than ordinary discursive language. Nevertheless, the hinting nature of the communication has a protective function, and it insures against disappointment. He views hysteria as a "metagame”, where ethical choices are made about how to live.

The second contribution is the parallel he draws between the scapegoating of witches during the Inquisition, and the scapegoating of “madmen” in the Mental Health Movement (Szasz, 1971). The Mental Health Movement is said to consider social nonconformity as mental illness. He posits that psychiatric diagnoses are the modern tools that psychiatrists (as agents of the state) use to scapegoat (discriminate against) patients (deviants) who do not conform to societal norms. He says society sacrifices some of its members to purify itself and thus maintain its integrity and survival. The victims are invariably considered not (fully) human beings. Szasz also comments on the oppression of women as an example of such scapegoating.

The third contribution is the parallel he draws between religion and medicine (Szasz, 1979) on the grounds of universalities: Whereas in the past the universality of sin led people to become penitents of their priests, nowadays (1979) the universality of suffering leads people to become patients of their physicians. In his words: "In the Age of Medicine, men and women have to, and 
want to, call their spiritual problems sicknesses and their spiritual authorities doctors, who, in turn, call them patients." Furthermore, he argues that if a person's account of him- or herself is incomprehensible, they are declared insane.

I also draw a bit on Potter's summary of postcolonial feminist theory and postmodernist feminism in her paper on key feminist concepts (Potter, 2001). One of the effects of colonization is said to be the internalization by the colonized of the values and judgments imposed upon them, including the internalization of intimations of inferiority. This is called internalized oppression or psychological oppression (Fanon and Bartky, as referred to in Potter 2001). However, the colonized person retains a sense of him- or herself as belonging to a different group. The colonized person's moving between different contexts results in what might be considered a normal phenomenon of “double consciousness” (Fanon and Lugones, as referred to in Potter 2001). According to postmodernist feminism, traditional discursive practices support a male symbolic order (Irigaray and Cixous, as referred to in Potter 2001), and hence (freely extrapolated) the only way of communicating without invoking the male symbolic order is through using the female body.

Let us now interpret experimentally self-injury in women diagnosed with BPD as symbolic sacrifice or symbolic self-assertion in the light of the contributions by Szasz and the above two feminist theories. Self-injury might then be interpreted as an iconic-symbolic message that the perpetrator is suffering from some sort of spiritual problem (cf. Szasz 1961, 1979). The problem is most likely a moral conflict about some form of social nonconformity and probably concerns oppressive societal norms for women. Let us assume that in this instance it has something to do with anger about the moral injustice of the dehumanization of women. True to both the Age of Medicine and the era of body commodification, the sufferer expresses her spiritual problem/moral conflict appropriately as a body problem (self-inflicted bodily injury). She thus rehumanizes herself by transforming her body into that of a person in need of medical attention, that is, a fellow human being of the physician. She sacrifices the right sort of thing for the "priest of the day", (her commodified body for her physician), thereby affirming her identity as a person. The sacrifice might also serve as self-punishment (through internalized oppression) for her violation of oppressive societal norms for women, by for example her resistance to body commodification or her resistance to societal reduction of women to mere bodies. Through her sacrifice she transcends the "sin" of misogyny and accomplishes purification.

The plot thickens, though, because of the complex nature of the iconic-symbolic message. Superficially, the message might be: "I am sick (bleeding), therefore you should take care of me.” On another level, the message might be one of symbolic self-assertion: “There is no way of denying 
now that I am a fully human being with an affirmed identity, because I qualify for good medical care (i.e., the suturing up of my wounds).” The physician (as appointed agent of the Age of Medicine) now starts to feel uneasy about this patient, because the patriarchal idea of women as inferior beings is being challenged. On yet another level, the message might be: "You, the paternalistic physician, as a coperpetrator of the patriarchal sin of dehumanizing and alienating women, shall atone for that sin on behalf of all society, as I force you to descend to my level to give me the care (and respect) that is due to me.” The physician now feels distinctly uncomfortable and manipulated, because she or he is forced to subscribe simultaneously (albeit subconsciously) to opposing points of view: "women are mere bodies" (which justifies the atonement) and "women are fellow human beings in need of care” (which dictates the suturing of the wounds).

Furthermore, the physician does not understand this strange, primitive form of communication. The patient might be in the internally oppressed state of double consciousness at the time of the sacrificial encounter with the physician. Or she might be stuck in the mode of body communication, which defies the male symbolic order. Either way, she is probably unable at that time to help the physician, through using traditional (male symbolic order invoking) discursive language, to understand her problem of moral conflict. Moreover, there is too little common ground by which the physician can receive the patient's meaning (cf. Potter 2003). The incomprehensibility of the communication then leads the physician to declare the patient insane.

The sacrificial nature of the self-injury gets another twist when the patient is subsequently seen by the psychiatrist or psychologist. This clinician also experiences the (seemingly unjustified) blame that emanates from the patient, turns the blame back onto the patient by accusing her of using the defense of projective identification, resents and resists her manipulative behavior, and finds it very difficult to muster empathy, let alone give uptake to her own interpretations of her problems. Society (and psychiatry) might not have minded so much if this patient punished herself only, but here the patient also punishes the clinician as a representative of the oppressive society. The psychiatrist then succumbs to the societal task of scapegoating and proceeds to diagnose this dissociating deviant who participates in the taboo of self-mutilation and does not conform to the societal norms for women and their bodies. Thus, society sacrifices this patient (and all others that might try similar iconic communications in the future) to accomplish purification and maintain its status quo. Hence, a double-edged sacrifice.

The idea of making amends and having amends made for alienation in the context of selfinjury is not new, as can be seen from the following three accounts by patients who mutilate themselves, as reported by Favazza (1989): A 28-year old librarian said, “When 'it' strikes, self- 
mutilation is the only thing that provides relief; 'it' being a frantic, desperate, profound sense of alienation from the rest of the world...”. A 22-year-old secretary said: “This is how deeply you have hurt me." A 40-year-old disabled woman said: “I feel I am regarded as immature by doctors or friends when I ask for help. Thus, cutting satisfies a need for justice and fairness, and I am not compelled to turn my heart against those who have failed me." In similar vein, Miller's study of life history narratives of 10 patients with BPD revealed multiple references by each patient to feeling estranged from others and inadequate in the face of perceived social standards (Miller 1994).

Clinicians are morally manipulated and caught in a double bind in the above experimental scenario (which represents just one possibility from among many other possibilities). If we do not give uptake, we negate and trivialize the spiritual problem or the moral conflict of the patient, thus endorsing societal oppression of women and preserving our preconceived association between social deviance and mental pathology. If we do give uptake, we in effect accede to atoning for the "sins" of society, and acknowledge that we are rendered helpless and ineffective as healers in the traditional sense. Giving uptake properly is very difficult or even impossible under such circumstances. The proper giving of uptake would depend on a rethinking on the part of clinicians about our social role and function.

This commentary on Potter's paper has aimed to provide a brief overview of her argument that, notwithstanding possible theoretical significations of self-injury, clinicians have a duty to give uptake to the patient's own interpretations about the meaning of the self-injury. However, I argue that giving uptake can be very difficult for clinicians, and that an appreciation of this difficulty depends on an expansion and linkage of some of the theories that she touched on. Self-injury was experimentally revisited as a double-edged sword of symbolic sacrifice and iconic-symbolic selfassertion. This revisiting aimed to illustrate how clinicians might be caught in a double bind, and rendered incapable of giving uptake properly.

\section{REFERENCES:}

Barker, P. 1992. Basic family therapy, $3^{\text {rd }}$ ed. New York: Oxford University Press.

Boscolo, L., G. Cecchin, L. Hoffman, and P. Penn. 1987. Milan Systemic Family Therapy: Conversations in theory and practice. New York: Basic Books.

Campbell, D., and R. Draper, eds. 1985. Applications of Systemic Family Therapy: The Milan approach. London: Grune \& Stratton, Harcourt Brace Jovanovich.

Cecchin, G. 1987. Hypothesizing, circularity, and neutrality revisited: An invitation to curiosity. Family Process 26:405-13.

Favazza, A.R. 1989. Why patients mutilate themselves. Hospital and Community Psychiatry 40:137-45. 
Miller, S.G. 1994. Borderline personality disorder from the patient's perspective. Hospital and Community Psychiatry 45:1215-19.

Potter, N. 2003. Commodity/body/sign: Borderline personality disorder and the signification of self-injurious behavior. Philosophy, Psychiatry, \& Psychology 10:1-16.

Potter, N. 2001. Feminism. Philosophy, Psychiatry, \& Psychology 8:61-71.

Selvini, M. P., L. Boscolo, G. Cecchin, and G. Prata. 1980. Hypothesizing - circularity - neutrality: Three guidelines for the conductor of the session. Family Process 19:3-12.

Szasz, T.S. 1961. The myth of mental illness: Foundations of a theory of personal conduct. New York: Dell.

Szasz, T. S. 1971. The manufacture of madness: A comparative study of the inquisition and the mental health movement. London: Routledge \& Kegan Paul.

Szasz, T. S. 1979. The theology of medicine: The political-philosophical foundations of medical ethics. Oxford: Oxford University Press. 